\title{
La aplicación de la justicia intercultural en materia penal desde el derecho a la identidad cultural de los procesados.
}

The application of intercultural justice in criminal matters from the right to the cultural identity of the accused

\author{
Hugo Zambrano Vera* \\ Investigador jurídico independiente \\ Infomación del Artículo \\ Original - Ruptura, 2020 \\ Artículo recibido / Received: 8 de octubre 2020 \\ Artículo aceptado / Accepted: 10 de diciembre, 2020

\section{Citación} \\ Zambrano, H. (2020). La aplicación de la justicia intercultural en materia penal \\ desde el derecho a la identidad cultural de los procesados. Revista Ruptura de la \\ Asociación Escuela de Derecho PUCE. Edición 2020, p (431-453).
}

DOI: $10.26807 /$ rr.vi02.33

Resumen: El problema más sobresaliente en la aplicación de la justicia intercultural en Ecuador es el conflicto de competencia entre la justicia indígena y la justicia ordinaria cuando conocen de un hecho que puede ser penalmente relevante. Aunque el legislador y la jurisprudencia han tratado de regular el ámbito de actuación de cada una de ellas, lo cierto es que en sus disquisiciones no han considerado el derecho a la identidad cultural de los sujetos activos del delito como factor dirimente para la solución de este problema. El objetivo general de este trabajo es realizar un estudio sobre la aplicación de la

* Estudiante egresado de la Escuela de Jurisprudencia de la Pontificia Universidad Católica del Ecuador - Sede Ibarra (2020). Correo electrónico: hugozambrano794@gmail.com. 
justicia intercultural en materia penal, a partir del respeto al derecho a la identidad cultural de los procesados, mediante una investigación documental, con el fin de hallar el camino que permita emplearla de manera efectiva y eficaz dentro del marco jurídico ecuatoriano. Esta investigación se abordó desde un enfoque cualitativo empleando los métodos analítico y antropojurídico y, como consecuencia de la misma, se propone una solución a partir de la creación y aplicación de algunas reglas que deberían ser tomadas en cuenta, en lo sucesivo, por los operadores de justicia en su actividad judicial.

Palabras clave: Competencia, identidad cultural, justicia intercultural, derecho procesal penal, reglas.

\begin{abstract}
In the case that there are criminally relevant facts, the most outstanding problem in the application of intercultural justice in Ecuador is the conflict of jurisdiction between indigenous justice and ordinary justice. Although the legislator and jurisprudence have tried to regulate the scope of each application, the truth is, that in their disquisitions they have not considered the right to cultural identity of the active subjects of the crime as a decisive factor for the solution of this trouble. The general objective of this work is to carry out a study of the application of intercultural justice in criminal matters. This investigation is based on respect for the right to cultural identity of the defendants, through documentary research, in order to discover a way to use it effectively and efficiently within the Ecuadorian legal framework. This research was approached from a qualitative analysis using anthropo-legal methods. As a consequence, a solution is proposed based on the creation and application of rules of accountability and administered by the operators of Justice within the framework of judicial activity.
\end{abstract}

Keywords: Competence, cultural identity, intercultural justice, criminal procedural law, rules. 


\section{Introducción}

Uno de los hitos de la Constitución ecuatoriana de 2008 es la protección que brinda a la existencia del sistema jurídico ancestral de los pueblos, comunidades y nacionalidades indígenas, quienes despiertan admiración y respeto por haber preservado sus costumbres pese a los intentos de asimilación cultural emprendidos desde el Estado ${ }^{1}$, el cual, a través de sus representantes, ha reconocido finalmente la deuda histórica que tiene con estos grupos tradicionalmente marginados.

En la segunda mitad del siglo XX, con el surgimiento de las luchas sociales de la clase proletaria, también se dieron los primeros levantamientos indígenas de la era contemporánea de nuestro país ${ }^{2}$ que exigían, a quienes detentaban el poder, igualdad en la aplicación de la ley, respeto para su identidad cultural, mejores condiciones de calidad de vida y la consideración de su opinión a la hora de tomar decisiones que pudieran afectarles. En esa misma época también surgieron varios instrumentos internacionales orientados a la protección de los derechos humanos de los pueblos ancestrales como el Convenio No. 169 de la Organización Internacional del Trabajo (OIT) Sobre Pueblos Indígenas y Tribales y la Declaración de las Naciones Unidas

1 Sobre los intentos de asimilación cultural orquestados por el Estado hacia los pueblos, comunidades y nacionalidades indígenas el historiador Enrique Ayala Mora (2008) señala que estos pueden dividirse en tres periodos, a saber: (i) el Proyecto Nacional Criollo, que plantea la continuidad de las relaciones de sojuzgamiento entre indígenas y los descendientes de los españoles en América (criollos); (ii) el Proyecto Nacional Mestizo, en el que se reconoció la existencia de los pueblos indígenas pero buscando extinguir sus costumbres implantando la cultura occidental con el fin de aplicar (erradamente) el principio de igualdad; y, (iii) el Proyecto Nacional de la Diversidad en el que los pueblos indígenas surgen como actores del cambio social.

2 Mención especial merece el primer levantamiento indígena, que inició el 28 de mayo de 1990 con la toma pacífica de la iglesia de Santo Domingo, en el centro histórico de Quito y que en los días siguientes convocó a los pueblos indígenas de la sierra norte, centro y de la región amazónica. (Confederación de Nacionalidades Indígenas del Ecuador, 2020). 


\section{La aplicación de la justicia intercultural en materia penal desde el derecho a la identidad cultural de los procesados}

sobre los Derechos de los Pueblos Indígenas; en dichos documentos se defiende, entre otras cosas, la potestad de estos grupos humanos para administrar justicia de acuerdo con sus tradiciones ancestrales, siempre que al hacerlo no se vulneren derechos humanos ${ }^{3}$.

Ahora bien, muchos instrumentos internacionales de Derechos Humanos no llegan a aplicarse por parte de los Estados signatarios, pues estos se escudan en la idea de que dichos postulados sólo son aplicables, debido a que el ordenamiento jurídico interno de cada país prevé normas que regulen su ejercicio, por eso se tiene la impresión de que el contenido de dichos documentos no pasa de ser un conjunto de ideas utópicas cuya práctica no se realiza si no existe una ley que desarrolle su contenido; esta idea, en el caso de los pueblos ancestrales, se refuerza al considerar que quienes pertenecen a dichos grupos humanos siguen siendo vistos como seres inferiores, que no saben lo que quieren y a quienes se debe "civilizar".

No obstante, este sector social ha venido luchando por la reivindicación de sus derechos, entre los cuales se encuentran la identidad cultural, la autodeterminación y, dentro de estos, la administración de su propia justicia. Reconociendo esta realidad, la Constitución ecuatoriana de 1998 consagró, en el inciso tercero de su artículo 191, el derecho de estos pueblos a ejercer "funciones de justicia, aplicando normas y procedimientos propios para la solución de conflictos internos de conformidad con sus costumbres o derecho consuetudinario, siempre que no sean contrarios a la Constitución y las leyes";

3 El numeral 1 del artículo 9 del Convenio 169 de la OIT manifiesta que "en la medida en que ello sea compatible con el sistema jurídico nacional y con los derechos humanos internacionalmente reconocidos, deberán respetarse los métodos a los que los pueblos interesados recurren tradicionalmente para la represión de los delitos cometidos por sus miembros". Del mismo modo, el artículo 5 de la Declaración de las Naciones Unidas sobre los Derechos de los Pueblos Indígenas señala que: "Los pueblos indígenas tienen derecho a conservar y reforzar sus propias instituciones políticas, jurídicas, económicas, sociales y culturales, manteniendo a la vez su derecho a participar plenamente, si lo desean, en la vida política, económica, social y cultural del Estado". 
la Carta Política de aquel entonces también afirmó que "La ley hará compatibles aquellas funciones con las del sistema judicial nacional" y estos postulados que se mantienen, en lo esencial, en el artículo 171 la Constitución ecuatoriana de $2008^{4}$.

Al proteger constitucionalmente la administración de justicia indígena, el constituyente - tanto en 1998 como en 2008 - fue consciente de que existirían dificultades para su aplicación pues, hasta ese momento, gracias a la influencia del positivismo kelseniano, el juez ordinario, al haber recibido potestad estatal, era el único competente para aplicar la ley a partir de su contenido literal (Kelsen, 2015). Adicionalmente, muchos miembros de la sociedad ecuatoriana, al observar la aplicación del sistema de justicia indígena practicada por la comunidad hacia el sujeto infractor - a través del baño con agua fría, los golpes con plantas de ortiga, el látigo, entre otros (Pérez, 2015) - piensan que estos son actos de "salvajismo y tortura" que se dan como consecuencia de "hacer justicia por su propia mano", actitud que en algunas ocasiones ha sido alentada por varios medios de comunicación al presentar las noticias sobre estos hechos de manera sesgada y fuera de su contexto cultural (Ávila, 2016, p. 47).

Este tema tiene especial relevancia en materia penal, ya que se ha comprobado que la aplicación de la llamada justicia ordinaria no rehabilita al indígena que es sometido a su jurisdicción por haber cometido un delito, todo lo contrario, puede causarle varios traumas, pues este conglomerado social no entiende a la Justicia como la imposición de

4 Art. 171.- Las autoridades de las comunidades, pueblos y nacionalidades indígenas ejercerán funciones jurisdiccionales, con base en sus tradiciones ancestrales y su derecho propio, dentro de su ámbito territorial, con garantía de participación y decisión de las mujeres. Las autoridades aplicarán normas y procedimientos propios para la solución de sus conflictos internos, y que no sean contrarios a la Constitución y a los derechos humanos reconocidos en instrumentos internacionales. El Estado garantizará que las decisiones de la jurisdicción indígena sean respetadas por las instituciones y autoridades públicas. Dichas decisiones estarán sujetas al control de constitucionalidad. La ley establecerá los mecanismos de coordinación y cooperación entre la jurisdicción indígena y la jurisdicción ordinaria (CRE, 2008). 


\section{La aplicación de la justicia intercultural en materia penal desde el derecho a la identidad cultural de los procesados}

un castigo, sino como un proceso de purificación que consiste en recuperar la armonía consigo mismo, con los agraviados, con la Naturaleza (Pacha Mama), con sus familias y con la comunidad (Ávila, 2016, p. 45).

Sin embargo, aunque se observan esfuerzos para regular la aplicación armónica de ambas formas de administrar justicia, la realidad es que no es extraño observar el juzgamiento de personas pertenecientes a los pueblos, comunidades y nacionalidades indígenas por parte de los jueces de justicia ordinaria, quienes terminan imponiéndoles sanciones según la cultura occidental (prisión, multas, pérdida de derechos de participación e interdicción); así como tampoco sorprende que los medios de comunicación informen de procesos de justicia indígena en los que los sancionados son personas que no pertenecen a dichos pueblos, comunidades y nacionalidades, como cuando "los habitantes de la comunidad de Peguche, en Otavalo (Imbabura), castigaron (...) a tres personas, acusadas de robar un vehículo" (El Comercio, 2019), las cuales no fueron reconocidas como moradores del sector sino como ciudadanos extranjeros procedentes de Venezuela (El Universo, 2019) ${ }^{\circ}$, o cuando "en el mercado artesanal de Otavalo, conocido como La Plaza de Ponchos, en la provincia de Imbabura, un hombre acusado de robar víveres de un minimarkert (valorados en USD $\$ 65,00$ dólares) fue ajusticiado" (El Universo, 2019) ante la mirada del personal policial, quienes no pudieron comprobar si el ciudadano infractor se identificaba como indígena, por lo que se limitaron a presenciar el

5 Según Ramiro Ávila Santamaría (2016), la única medida realmente sancionadora que aplica la justicia indígena es la expulsión del individuo de la comunidad a la que pertenece, con posibilidad (según el caso) de que pueda volver a ella después de algunos años.

6 Tres hombres de nacionalidad venezolana, sospechosos de robar un vehículo la noche del domingo, fueron retenidos por otavaleños que los habrían descubierto. (...). Cerca de las 09:00 el Cabildo desarrollo una asamblea para determinar el castigo indígena a los tres supuestos ladrones. Mientras los retenidos permanecían vendados los ojos y atadas las manos. A las 11:00 culminó la asamblea en la que se determinó el castigo para los tres sospechosos que fue el de aplicar el baño ritual de la comunidad, ortigazos y luego los azotes. (El Universo, 2019). 
castigo al que fue sometido; Asimismo, una noticia presentada por el diario La Hora (2016) manifesta que:

Un grupo de indígenas, quienes vinieron de las provincias de Cotopaxi y Chimborazo, querían aplicar su justicia a tres sospechosos de asesinar a un pastor evangélico. Ocurrió en el sector de Caupicho, en el sur de Quito. (...). Según versiones de los presentes, la turba de indígenas incendió la casa en la que vivían los presuntos asesinos, quienes eran identificados por los moradores del sector como delincuentes, pues eran quienes ‘sembraban el terror' en el barrio.

Ante esta realidad, es preciso recordar que de acuerdo con el artículo 1 de la Constitución, en concordancia con el artículo 24 del Código Orgánico de la Función Judicial (COFJ), las relaciones entre la justicia indígena y la justicia ordinaria tienen su soporte en el principio de interculturalidad, de tal manera que el objetivo consistente en la aceptación, respeto e interrelación con las demás culturas (Bernabé, 2012, p.70), a partir de las peculiaridades de cada una de ellas.

Así, se evidencia que las normas que regulan la competencia entre ambas jurisdicciones no consideran la identidad cultural de los procesados, y esta es una de las razones por las cuales ha sido difícil llegar a clarificar el ámbito de actuación de cada una de ellas. En efecto, no parece justo que una persona mestiza que ha cometido un delito dentro de una comunidad indígena sea juzgada mediante un proceso que no entiende o con el cual no se siente culturalmente identificado $\mathrm{y}$, lo mismo puede decirse de una persona perteneciente a los pueblos ancestrales y que comete un delito fuera de su comunidad, por ello la pregunta que guía la presente investigación es ¿Cómo aplicar la justicia intercultural, en materia penal, a partir del respeto al derecho a la identidad cultural de los procesados?

El objetivo general de este trabajo - que se desarrolló como un proyecto independiente - es realizar un estudio sobre la aplicación de la justicia intercultural en materia penal, a partir del respeto al derecho a la identidad cultural de los procesados, mediante una investigación documental, con el fin de emplearla de manera efectiva y eficaz dentro del marco jurídico ecuatoriano. Para ello, también se han planteado los 
siguientes objetivos específicos: (i.) Analizar las fuentes legales existentes en Ecuador en materia de justicia intercultural; y, (ii.) establecer reglas que permitan aplicar la justicia intercultural en el contexto jurídico y social ecuatoriano de forma clara y en respeto al derecho a la identidad cultural de los procesados.

Los principales beneficiados e involucrados en este estudio son los pueblos comunidades y nacionalidades indígenas, los legisladores y los administradores de justicia, puesto que en el presente trabajo pueden encontrar argumentos suficientes para la transformación de las relaciones entre la justicia ordinaria e indígena, a fin de que cada una de ellas tenga competencia amplia y suficiente para juzgar los presuntos delitos que se pongan en su conocimiento en un marco de respeto a la identidad cultural de los acusados, misma que forma parte de sus derechos humanos y constitucionales.

\section{Metodología}

El enfoque con el que se abordó este trabajo fue cualitativo, puesto que se ha realizado una reflexión acerca de la forma en que debe aplicarse la justicia intercultural desde el punto de vista del derecho a la identidad cultural, mismo que no suele ser considerado de forma suficiente por los administradores de justicia ordinarios e indígenas a la hora de iniciar el proceso en contra de los presuntos infractores que habrían cometido un delito.

Los métodos que se emplearon fueron el analítico y el antropojurídico. El primero, a partir del estudio y reflexión sobre varias disposiciones legales halladas en el ordenamiento jurídico ecuatoriano se obtuvieron algunas reglas que pueden ayudar a dirimir los conflictos de competencia entre la justicia indígena con la justicia ordinaria. Por medio del segundo método, se profundizó en el análisis del problema de investigación y de la solución al mismo desde el derecho a la identidad cultural de los presuntos infractores.

Para llevar a cabo lo anterior se empleó la técnica de revisión documental de varios textos de relevancia jurídica como la Constitución 
de la República del Ecuador (CRE), el Código Orgánico de la Función Judicial (COFJ), el Código Orgánico Integral Penal (COIP), algunas sentencias y decisiones jurisprudenciales, varios instrumentos internacionales referentes a los pueblos indígenas, así como aportes doctrinales y artículos científicos relacionados con la presente investigación; los instrumentos utilizados para la recopilación y clasificación de la información mencionada fueron las fichas de resumen.

\section{Resultados}

El artículo 21 de la Constitución del Ecuador señala que "Las personas tienen derecho a construir y mantener su propia identidad cultural, a decidir sobre su pertenencia a una o varias comunidades culturales y a expresar dichas elecciones" (CRE, 2008), en este sentido, la Corte Constitucional (2018), en la sentencia No. 001-18-PJO-CC, con respecto a la vigencia de los derechos, afirma que "es obligación del Estado abstenerse de intervenir arbitraria e innecesariamente en los derechos y libertades de los ciudadanos, así como garantizar su plena efectividad".

Reforzando lo anterior, la Norma Suprema, al preveer la existencia de la justicia indígena señala, en el segundo inciso del artículo 171, que "La ley establecerá los mecanismos de coordinación y cooperación entre la jurisdicción indígena y la jurisdicción ordinaria" (CRE, 2008), para lo cual debe aplicarse el principio de interculturalidad que se expresa en el artículo 24 del COFJ en los siguientes términos:

En toda actividad de la Función Judicial, las servidoras y servidores de justicia deberán considerar elementos de la diversidad cultural relacionados con las costumbres, prácticas, normas y procedimientos de las personas, grupos o colectividades que estén bajo su conocimiento. En estos casos la servidora y el servidor de justicia buscará el verdadero sentido de las normas aplicadas de conformidad a la cultura propia del participante ${ }^{7}$.

7 En el citado artículo, de alguna manera, también se hace referencia a la obligación que tienen los servidores de la Función Judicial, especialmente jueces y fiscales, de aplicar el control de convencionalidad a fin de garantizar la vigencia 


\section{La aplicación de la justicia intercultural en materia penal desde el derecho a la identidad cultural de los procesados}

Ahora bien, el principio de interculturalidad - al aplicarse en la Función Judicial - se traduce en la creación de la justicia intercultural, misma que se rige por cinco principios contenidos en el artículo 344 del Código "ibidem", los cuales son: diversidad, igualdad, non bis in ídem, pro jurisdicción indígena e interpretación intercultural ${ }^{8}$.

También hay que reconocer que han sido varias las acciones llevadas a cabo por el Estado para tratar de armonizar las relaciones

del derecho a la identidad cultural de las personas inmersas en el proceso penal, por lo que la responsabilidad de aplicar lo dispuesto en esta norma es doble: como ejercicio del derecho a la seguridad jurídica y como cumplimiento de la normativa internacional y constitucional en materia de derechos.

Art. 344.- Principios de la justicia intercultural.- La actuación y decisiones de los jueces y juezas, fiscales, defensores y otros servidores judiciales, policías y demás funcionarias y funcionarios públicos, observarán en los procesos los siguientes principios: a) Diversidad.- Han de tener en cuenta el derecho propio, costumbres y prácticas ancestrales de las personas y pueblos indígenas, con el fin de garantizar el óptimo reconocimiento y realización plena de la diversidad cultural; b) Igualdad.- La autoridad tomará las medidas necesarias para garantizar la comprensión de las normas, procedimientos, y consecuencias jurídicas de lo decidido en el proceso en el que intervengan personas y colectividades indígenas. Por lo tanto, dispondrán, entre otras medidas, la intervención procesal de traductores, peritos antropólogos y especialistas en derecho indígena. c) Non bis in idem.- Lo actuado por las autoridades de la justicia indígena no podrá ser juzgado ni revisado por los jueces y juezas de la Función Judicial ni por autoridad administrativa alguna, en ningún estado de las causas puestas a su conocimiento, sin perjuicio del control constitucional; d) Pro jurisdicción indígena.- En caso de duda entre la jurisdicción ordinaria y la jurisdicción indígena, se preferirá esta última, de tal manera que se asegure su mayor autonomía y la menor intervención posible; y, e) Interpretación intercultural.- En el caso de la comparecencia de personas o colectividades indígenas, al momento de su actuación y decisión judiciales, interpretarán interculturalmente los derechos controvertidos en el litigio. En consecuencia, se procurará tomar elementos culturales relacionados con las costumbres, prácticas ancestrales, normas, procedimientos del derecho propio de los pueblos, nacionalidades, comunas y comunidades indígenas, con el fin de aplicar los derechos establecidos en la Constitución y los instrumentos internacionales. 
entre la justicia indígena y la justicia ordinaria, siendo las más destacadas, por parte de la Función Legislativa, la creación del COFJ, en donde se desarrolla el principio de interculturalidad y se prevén algunos lineamientos que regulan las relaciones entre ambos tipos de justicias ${ }^{9}$. Adicionalmente, desde 2018, se ha venido impulsando el Proyecto de Ley Orgánica para la Aplicación de la Justicia Indígena en Ecuador, aunque todavía no se lo ha discutido en el pleno de la Asamblea Nacional (Observatorio Legislativo, s/f) ${ }^{10}$.

Por su parte, la Función Ejecutiva, a través del Ministerio de Gobierno y de la Policía Nacional, ha venido organizando varias conferencias, capacitaciones, seminarios y simposios destinados a compartir conocimientos y puntos de vista y dialogar con los diferentes actores de esta realidad, a fin de obtener orientaciones para la actuación del personal policial ante este tipo de casos $^{11}$.

Para la Función Judicial no existe una línea de argumentación jurídica clara respecto a su actuación al conocer conflictos de competencia entre la justicia indígena y la ordinaria en materia penal. Sin embargo, la Resolución No. 154-2015, dictada mediante sentencia de casación por la Sala de lo Penal, Penal Militar, Penal Policial y Tránsito de la Corte Nacional de Justicia del Ecuador (2015), resolvió restar competencia a la Justicia Indígena, al conocer de un delito de violación sexual cometido por una persona

9 Las disposiciones que regulan la existencia entre ambos tipos de justicias se encuentran en el Título VIII: "Relaciones de la Jurisdicción Indígena con la Jurisdicción Ordinara”, que comprende los artículos 343 - 346.

10 El proyecto de ley fue presentado por el asambleísta Juan Cárdenas Espinoza y, mediante Resolución CAL-2017-2019-637 del Consejo de Administración Legislativa, de fecha 20 de febrero de 2019, fue calificado y remitido a la Comisión Especializada Permanente de los Derechos Colectivos, Comunitarios y la Interculturalidad, para que inicie su tramitación (Consejo de Administración Legislativa de la Asamblea Nacional del Ecuador, 2019).

11 Entre ellos destaca el "I Simposio de justicia indígena y su implicación en la labor policial”, organizado por la Policía Nacional del Ecuador en conjunto con la Pontificia Universidad Católica del Ecuador - Sede Ibarra (Pabón, 2018). 


\section{La aplicación de la justicia intercultural en materia penal desde el derecho a la identidad cultural de los procesados}

adolescente, perteneciente a una de las nacionalidades indígenas, hacia otra persona de su misma comunidad, el tribunal, aplicando el principio de interculturalidad decidió:

1.- Sustituir la medida socioeducativa privativa de libertad impuesta. 2.- La comunidad (...), reunida en asamblea, determinará y asignará al adolescente procesado actividades comunitarias, en horario y tiempo compatible con los estudios; quedan prohibidas todas las actividades que pongan en riesgo su integridad personal. 3.- El adolescente pedirá disculpas públicas a la víctima, a su familia, a su propia familia; y, a la comunidad toda. 4.- De conformidad con el artículo 385.3, último inciso del Código de la Niñez y Adolescencia, el adolescente deberá asistir a charlas informativas sobre salud sexual y reproductiva con enfoque intercultural y de derechos humanos, con la asistencia y supervisión de la oficina técnica de la Unidad Judicial de la Familia Mujer y Adolescencia (...) que elaborará informes mensuales.

Finalmente, la Corte Constitucional del Ecuador, a través de su jurisprudencia, también se ha pronunciado aunque limitando el derecho de estos pueblos a administrar su propia justicia en los delitos contra la vida. En 2014, La Corte Constitucional mediante la sentencia No. 113-14-SEP-CC, conocida también como el caso La Cocha II, manifestó que:

La jurisdicción y competencia para conocer, resolver y sancionar los casos que atenten contra la vida de toda persona, es facultad exclusiva y excluyente del sistema de Derecho Penal Ordinario, aun en los casos en que los presuntos involucrados y los presuntos responsables sean ciudadanos pertenecientes a comunidades, pueblos y nacionalidades indígenas, así los hechos ocurran dentro de una comunidad, pueblo o nacionalidad indígena (Corte Constitucional del Ecuador, 2014, p. 35).

Esta decisión, en el informe emitido en 2019 la Relatora Especial sobre los derechos de los pueblos indígenas, fue calificada como un "retroceso sufrido en el adecuado reconocimiento del pluralismo jurídico [puesto que] ni los estándares internacionales ni la propia Constitución señalan este tipo de limitaciones" (Asamblea General de las Naciones Unidas, 2019, párr. 48), por lo que, junto con otras 
decisiones emitidas por la autoridad judicial han sido presentadas ante la Comisión Interamericana de Derechos Humanos (2018) como "Denuncias de criminalización por el ejercicio de la jurisdicción indígena en Ecuador", esperando hasta la fecha, un pronunciamiento oficial sobre este tema. No obstante, la Corte Constitucional, en la sentencia jurisprudencial No. 134-13-EP/20, ha manifestado que:

(...) ante una solicitud de declinación de competencia, las juezas y juezas (Sic.) ordinarios deberán limitarse exclusivamente a verificar la existencia de un proceso de justicia indígena. En este sentido, dentro del término probatorio de tres días contemplado en el artículo 345 del COFJ, al analizar la pertinencia de tal invocación, los jueces ordinarios se limitarán a verificar la existencia del proceso de justicia indígena. En ningún caso, los jueces ordinarios examinarán el sentido de la respectiva decisión, incluso si ya existiese un proceso en la justicia común sobre el mismo asunto. Esto, a su vez, asegura el respeto al derecho a ser juzgado por el juez competente conforme lo reconoce el artículo 76 numeral 3 de la Constitución (Corte Constitucional del Ecuador, 2020, párr. 54) ${ }^{12}$.

El artículo 76, numeral 3 de la Constitución expresa, entre otras cosas, que uno de los derechos del debido proceso es que "sólo se podrá juzgar a una persona ante un juez o autoridad competente y con observancia del trámite propio de cada procedimiento", la competencia, de acuerdo con Couture (2010) "es una medida de la jurisdicción" (p.24) y, de acuerdo con el artículo 156 del COFJ, se distribuye "en razón de las personas, del territorio, de la materia, y de los grados", reglas que también se aplican en la jurisdicción indígena. Llasag (2009), reflexionando sobre la regla de la competencia personal afirma que:

Para la determinación de la competencia en razón de la pertenencia étnica, surge una pregunta fundamental, ¿Cómo se determina la pertenencia

12 Puesto que la jurisprudencia no solo debe ser interpretada en su texto, sino también en su contexto, es necesario aclarar que esta decisión jurisprudencia no se aparta de lo dispuesto por este Organismo y vigilancia y control constitucional en el caso La Cocha II, puesto que para hacerlo se requiere una declaratoria expresa del pleno de la Corte, lo que en la especie no ha ocurrido. 


\section{La aplicación de la justicia intercultural en materia penal desde el derecho a la identidad cultural de los procesados}

étnica de una persona? o ¿Cuáles son los criterios para considerar a una persona miembro de un pueblo indígena? Este es un tema que debe dilucidar el Derecho indígena de cada uno de los pueblos, pero básicamente, se determina por: la autoidentificación de la persona como miembro o parte de un pueblo indígena y que ese pueblo indígena le considere como tal. Los pueblos indígenas generalmente consideran miembros a las personas que participan activamente en la vida comunitaria: que son fundamentalmente mingas, reuniones, aportes económicos e intelectuales y actos sociales (p. 193).

En otras palabras, la identidad cultural forma parte de la competencia personal y se compone de un elemento subjetivo (el sentimiento de pertenencia a una comunidad indígena) y de un elemento objetivo (la aprobación de la comunidad como parte de la misma). Sin embargo, asumir la pertenencia hacia un grupo en razón de la etnia no traería necesariamente, como consecuencia, la pertenencia cultural hacia ese mismo grupo; en otras palabras, el hecho de que un indígena tenga los mismos rasgos físicos que sus semejantes no implica que pertenezca a la misma cultura puesto que, de acuerdo con Molano (2007):

El concepto de identidad cultural encierra un sentido de pertenencia a un grupo social con el cual se comparten rasgos culturales, como costumbres, valores y creencias. La identidad no es un concepto fijo, sino que se recrea individual y colectivamente y se alimenta de forma continua de la influencia exterior (p.73).

Así mismo, según González (1999), la identidad de los conglomerados sociales "viene definida históricamente a través de múltiples aspectos en los que se plasma su cultura, como la lengua (...), las relaciones sociales, ritos y ceremonias propias, o los comportamientos colectivos, esto es, los sistemas de valores y creencias" (p.71), por ello los elementos descritos por Llasag sobre la pertenencia étnica también son aplicables a la pertenencia cultural, considerando que esta es un fenómeno de expresión social que engloba a la identidad étnica y que se ubica por encima de la misma; por esta razón, la competencia personal debe considerar este factor, pues de él depende que el proceso que se siga se realice en estricto apego a los derechos humanos. 
En este sentido, también hay que indicar que en los pueblos indígenas, por la globalización, han ido incorporando a su cosmovisión y mentalidad varios elementos de la cultura occidental, lo cual ha generado que surjan nuevos grupos que fusionan los elementos ancestrales con elementos propios de las culturas juveniles anglosajonas o asiáticas, por lo que no es sorprendente si una persona llega a identificarse con dos o más grupos culturales, hecho que torna difícil determinar, a primera vista, la identidad cultural del sospechoso; por ello lo más recomendable es preguntarle directamente con qué grupo cultural se identifica y, si fuese el caso de que lo hiciese con alguna de las comunidades de las nacionalidades indígenas, se debería verificar esta información con el cabildo de dicha comunidad, a efectos de determinar el sistema de justicia que ha de aplicarse para la resolución del conflicto.

\section{Discusión}

Al aplicar el Derecho Procesal Penal ecuatoriano se observa la existencia de varios problemas para una aplicación intercultural de los sistemas de justicia ancestral y occidental, pues ambos reclaman para sí la competencia en el juzgamiento y posterior sanción de las infracciones cometidas por las personas que pertenecen a estos pueblos o por individuos que, sin pertenecer a ellos, han llevado a cabo actos delictivos (o cuestionables para estos grupos de personas) dentro de su territorio, alterando la armonía de dicha comunidad. A pesar de ello se puede afirmar que ambos tipos de justicia están de acuerdo en afirmar que:

- Si una persona que pertenece a los pueblos, comunidades y nacionalidades indígenas comete una infracción dentro de su comunidad u observa una conducta moralmente cuestionable por sus cohabitantes debe ser procesado y purificado en el seno de la misma siguiendo, para ello, las tradiciones que la rigen y sin que deba intervenir la fuerza policial o la justicia penal ordinaria ya que su injerencia se considera, de forma inequívoca, como vulneración de su derecho a la autonomía. 


\section{La aplicación de la justicia intercultural en materia penal desde el derecho a la identidad cultural de los procesados}

- Del mismo modo, si una persona que no pertenece a los pueblos, comunidades y nacionalidades indígenas comete un delito fuera del territorio de dichos grupos, debe ser juzgada y, de ser hallada culpable, sancionada de acuerdo a la justicia ordinaria a través del proceso previsto en la ley. ${ }^{13}$

Ahora bien, cabe preguntarse: ¿Si un indígena es sospechoso de haber cometido un delito fuera de su comunidad qué autoridad es la competente para sancionarlo? Para responder a esta interrogante debemos considerar tres escenarios:

a. Que la conducta observada por el sospechoso - que pertenece a los pueblos comunidades y nacionalidades indígenas - se haya cometido en contra de una persona que no se identifique con la cultura indígena, encontrándose dicha acción u omisión tipificada en el Código Orgánico Integral Penal (COIP) y que la misma sea cuestionable también para su comunidad (como el robo, el hurto, el abigeato, la violación sexual, entre otros).

b. Que la conducta que haya observado el presunto infractor no sea cuestionable o no merezca ser sancionada desde la perspectiva del mundo indígena, pero sea punible en la justicia ordinaria (como el fraude procesal o el ingreso de artículos prohibidos).

c. Que la conducta antisocial se haya cometido por una persona de identidad cultural indígena hacia otro que también se identifique como tal, pero fuera de la comunidad territorial ancestral.

En el primer escenario, hay que considerar no solo la identidad cultural del investigado o procesado, sino también el derecho que tiene la víctima a recibir una reparación por el agravio cometido, por ello, es conveniente que el proceso de juzgamiento se lleve a cabo según la justicia ordinaria, pero las sanciones deberían administrarse aplicando el principio de interpretación intercultural señalado en el

13 Para esto último se ha de tener presente las reglas generales de la competencia de los jueces penales, previstas en el artículo 404 del COIP. 
literal e del artículo 344 del COFJ, para lo cual el juez debe consultar a los representantes de la comunidad indígena a fin de tomar con ellos las decisiones que mejor se ajusten para satisfacer a la víctima sin descuidar la identidad cultural del ciudadano infractor, para ello - tal como lo señala el numeral 2 del artículo 11 del Convenio 169 de la OIT - se dará "la preferencia a tipos de sanción distintos del encarcelamiento" pues, en el caso contrario, dentro del ejercicio de motivación que realicen los juzgadores se deberá justificar de forma minuciosa la insuficiencia de las sanciones alternativas a la cárcel y la utilidad de esta para que el indígena imputado se rehabilite de la conducta antisocial que ha ejercido. (Regla I). Lo anteriormente señalado aplicaría también para el segundo escenario (Regla II).

No obstante, si resulta que desde un análisis antropológico de la realidad cultural del procesado la conducta realizada no se encuentra considerada - desde su perspectiva - como una falta, podría operar el error de prohibición consagrado en el artículo 11 de La Ley Orgánica Reformatoria al Código Orgánico Integral Penal ${ }^{14}$ siempre y cuando se demuestre que es invencible, pues caso contrario se debería aplicar lo descrito en la Regla I (Regla III).

En el tercer escenario, lo procedente es remitir a las partes en conflicto ante el cabildo indígena (preferentemente de la comunidad a la que pertenezca la víctima) para que este convoque a la comunidad y se siga con el procedimiento ancestral previsto en sus tradiciones (Regla IV). En este sentido, no solo se debe esperar a que dichos pueblos soliciten la derivación de competencia, sino que es obligación de los operadores de justicia, como garantes del orden constitucional dentro del ámbito de sus competencias, poner en conocimiento de los pueblos ancestrales la existencia de estos hechos para que ellos decidan o ayuden a decidir sobre el tema de manera más justa y equitativa.

14 Artículo 11.- Agrégase a continuación del artículo 35 un artículo con el siguiente texto: "Art. 35.1.- Error de prohibición.- Existe error de prohibición cuando la persona, por error o ignorancia invencible, no puede prever la ilicitud de la conducta. Si el error es invencible no hay responsabilidad penal. Si el error es vencible se aplica la pena mínima prevista para la infracción, reducida en un tercio. 


\section{La aplicación de la justicia intercultural en materia penal desde el derecho a la identidad cultural de los procesados}

Por otro lado, también cabe preguntarse ¿Qué procedimiento se debe seguir - en apego a la interculturalidad - cuando una persona que no se identifica con la cultura de los pueblos, comunidades y nacionalidades indígenas comete un delito dentro de dicha comunidad o hacia una persona que pertenece a este grupo, pero cuya conducta se ejecuta fuera de su territorio ancestral? En este sentido también deben considerarse los siguientes escenarios:

a. Que una persona no indígena cometa un delito ${ }^{15}$ dentro del territorio de las comunidades indígenas.

b. Que el mismo tipo de persona cometa un delito en el que el sujeto pasivo del mismo sea una persona que pertenece a los pueblos indígenas.

c. Que una persona no indígena cometa un delito hacia otra persona que tampoco se considere culturalmente como indígena, pero los hechos se susciten al interior de una de estas comunidades.

d. Que una persona que no pertenece a los pueblos comunidades o nacionalidades indígenas realice un acto que no sea considerado como delito pero que sea considerado como ofensivo o atente contra las costumbres de este pueblo.

En todos los supuestos planteados dentro de los literales a, b y c lo justo - atendiendo, como se lo ha hecho a lo largo de este trabajo, al principio de identidad cultural - es que el infractor sea sancionado de acuerdo con la justicia ordinaria (Regla V), pues no es concebible que en un estado pluricultural y garantista de derechos se imponga una sanción incompatible con la identidad cultural del presunto sujeto activo, de lo contrario se vulneraría este derecho, para lo cual existe la posibilidad de presentar una acción extraordinaria de protección contra decisiones de la justicia indígena ${ }^{16} \mathrm{a}$ fin de que se

15 Es decir, una de las conductas consideradas como delito en el COIP.

16 Art. 65.- Ámbito.- La persona que estuviere inconforme con la decisión de la autoridad indígena en ejercicio de funciones jurisdiccionales, por violar los derechos 
repare el daño realizado hacia el infractor, sin perjuicio de las penas que le sean impuestas por el juez competente en caso de ser hallado culpable del delito.

Por lo que respecta la hipótesis planteada en el literal d, el sujeto no puede ser sometido a la justicia indígena, pero se encuentra obligado a presentar las debidas disculpas y reparar los daños que hubiese ocasionado (Regla VI), para ello - fomentando la cultura de paz a través del diálogo - se puede acudir ante los jueces de paz e incluso a los centros de mediación.

Finalmente, es importante subrayar que no se vulnera el principio de non bis in idem si una persona es sancionada con un sistema de administración de justicia con el que no se siente culturalmente identificado, puesto que lo contrario validaría la vulneración del derecho a la identidad a través de la violación de las reglas de competencia personal. Así mismo, las reglas enunciadas en este trabajo pueden y deben aplicarse antes de emplear el principio de in dubio pro justicia indígena, mismo que se convertiría en una herramienta procesal subsidiaria aplicable solo en el caso de que los hechos controvertidos que puedan presentarse no se encuadren en ninguno de los escenarios y reglas anteriores.

constitucionalmente garantizados o discriminar a la mujer por el hecho de ser mujer, podrá acudir a la Corte Constitucional y presentar la impugnación de esta decisión, en el término de veinte días de que la haya conocido. Se observarán los principios que, sobre esta materia, se encuentran determinados en la Constitución, instrumentos internacionales de derechos humanos de los pueblos y nacionalidades indígenas, demás instrumentos de derechos humanos, Código Orgánico de la Función Judicial y la ley. (Ley Orgánica de Garantías Jurisdiccionales y Control Constitucional). 


\section{Conclusiones}

En este trabajo se han delineado de forma puntual las reglas que, desde una perspectiva intercultural, deben ser consideradas para dirimir los conflictos de competencia entre la justicia indígena o ancestral con la justicia ordinaria en materia penal, por ello se constituyen en aclaraciones de lo establecido en el numeral 1 del artículo 404 del Código Orgánico Integral Penal, que parten del respeto al derecho a la identidad cultural de los sospechosos.

Este trabajo no pretende ser exhaustivo con sus proposiciones, más bien reta a los actores sociales de la administración de la justicia indígena y ordinaria (legisladores, jueces, fiscales y especialmente los representantes de los pueblos ancestrales) para concretar el procedimiento que ha de seguirse para armonizar ambas concepciones sin caer en un proceso burocrático y caer en la positivización de las costumbres que desde antaño han gobernado a los pueblos andinos originarios. En este sentido, vale recordar que un requisito previo para el diálogo es el conocimiento del otro (dialogar es uno de los requisitos para conocer al otro) y para ello, es necesario leer el libro Justicia Indígena de Yaku (Carlos) Pérez Guartambel, que expone de manera muy sencilla cómo viven estos pueblos su proceso de administración de justicia que más que condenar, sana.

\section{Referencias Bibliográficas}

Asamblea General de la Organización de las Naciones Unidas. (2007). Resolución A/Res/61/295. Declaración sobre los Derechos de los Pueblos Indígenas. Recuperado de https://www.un.org/esa/socdev/unpfii/documents/DRIPS_es.pdf

Asamblea General de la Organización de las Naciones Unidas. (2019). Infore de la Relatora Especial sobre los derechos de los pueblos indígenas A/ HRC/42/37 Add.1. Recuperado de https://documents-dds-ny.un.org/ doc/UNDOC/GEN/G19/204/08/PDF/G1920408.pdf?OpenElement 
Asamblea Nacional Constituyente del Ecuador. (1998). Constitución de la República del Ecuador. Registro Oficial No. 1

Asamblea Nacional Constituyente del Ecuador. (2008). Constitución de la República del Ecuador. Registro Oficial No. 449

Asamblea Nacional del Ecuador. (2009). Código Orgánico de la Función Judicial. Registro Oficial No. 544.

Asamblea Nacional del Ecuador. (2009). Ley Orgánica de Garantías Jurisdiccionales y Control Constitucional. Quito: Registro Oficial No. 52.

Asamblea Nacional del Ecuador. (2019). Ley Orgánica Reformatoria al Código Orgánico Integral Penal. Quito: Registro Oficial No. 107.

Ávila, R. (2016). El Neoconstitucionalismo Andino. Quito, Ecuador: Universidad Andina Simón Bolívar.

Ayala, E. (2008). Resumen de Historia del Ecuador. Quito, Ecuador: Corporación Editora Nacional.

Bernabé, M. (2012). Pluriculturalidad, multiculturalidad, interculturalidad, conocimientos necesarios para la labor docente. Revista Educativa Hejademos. 11 (5) pp.67-76. Recuperado de http://roderic.uv.es/bitstream/ handle $/ 10550 / 47898 / 081540 . p d f$ ?sequence $=1 \&$ isAllowed $=y$

Comisión Interamericana de Derechos Humanos. (2018). Ecuador: Criminalización de la Justicia Indígena. Recuperado de https://www.youtube. $\mathrm{com} /$ watch? $\mathrm{v}=08 \mathrm{NMp7YkPY8 \& index=16 \& list=PL5QlapyOGhXtxcMO-}$ pg35GCa2M7dJo_QVh\&t=0s

Confederación de Nacionalidades Indígenas del Ecuador. (2020). 1990: 30 años del primer gran levantamiento indígena. Recuperado de https:// conaie.org/2020/06/05/1990-30-anos-del-primer-gran-levantamiento-indigena/ 


\section{La aplicación de la justicia intercultural en materia penal desde el derecho a la identidad cultural de los procesados}

Consejo de Administración Legislativa de la Asamblea Nacional del Ecuador. (2019). Resolución CAL-2017-2019-637. Recuperado de https:// observatoriolegislativo.ec/media/archivos_leyes/Memorando_SAN2019-5046._Notificacion_Resolucion_CAL.pdf

Couture, E. (2010). Fundamentos del Derecho Procesal Civil. Buenos Aires, Aires: B de $\mathrm{f}$

El Comercio. (2019). Justicia indígena a tres acusados de intentar robar un vehículo en Otavalo. Recuperado de https://www.elcomercio.com/actualidad/justicia-indigena-robo-vehiculo-otavalo.html

El Universo. (2019). Otavaleños ajustician a tres venezolanoz implicados en robo de auto. Recuperado de https://www.eluniverso.com/noticias/2019/07/22/nota/7437522/otavalenos-pretenden-ajusticiar-venezolanos-implicados-robo-auto

González, I. (1999). Conservación de bienes culturales. Buenos Aires, Argentina: Cátedra.

Kelsen, H. (2015). Teoría Pura del Derecho. Madrid, Espeña: Trotta.

La Hora. (2016). Índigenas quieren aplicar su justicia a presuntos asesinos, Policía lo impide. Recuperado de https://lahora.com.ec/noticia/1101939079/indc3adgenas-quieren-aplicar-su-justicia-a-presuntos-asesinos-policc3ada-lo-impide

Llasag, R. (2009). La jurisdicción indígena en el contexto de los principios de plurinacionalidad e interculturalidad. En Andrade, S., Grijalva, A., y Storini, C. (Eds.). La nueva Constitución del Ecuador: Estado, derechos e instticuiones. Quito, Ecuador: Corporación Editora Nacional (pp.179-209).

Molano, O. (2007). Identidad cultural un concepto que evoluciona. Revista Opera 7 (7), pp.69-84. Recuperado de https://www.redalyc.org/ pdf/675/67500705.pdf 
Observatorio Legislativo. (s.f). Proyecto de Ley Orgánica para la Aplicación de la Justicia Indígena en Ecuador Tr. 336444 Recuperado de https://observatoriolegislativo.ec/legislacion/proyectos-de-ley/proyecto-de-ley-organica-para-la-aplicacion-de-la-justicia-indigena-en-el-ecuador-_9625

Organización Internacional del Trabajo. (1969). Convenio 169 de la Organización Internacional del Trabajo (OIT) Sobre Pueblos Indígnas y Tribales. Recuperado de https://www.ilo.org/dyn/normlex/es/f?p=NORMLEXPUB:12100:0::NO::P12100_ILO_CODE:C169

Pabón, G. (2018). PUCE-SI sede del I Simposio de justicia indígena y su Implicación en la Labor Policial. Recuperado de https://www.pucesi.edu. ec/webs/?p=6595

Pérez, C. (2015). Justicia Indígena. Quito, Ecuador: Universidad Estatal de Cuenca

\section{Jurisprudencia Constitucional}

Corte Constitucional del Ecuador. Sentencia No. 113-14-SEP-CC, Caso No. 0731-10-EP de 30 de julio de 2014. Juez ponente: Ruth Seni Pinoargote.

Corte Constitucional del Ecuador. Sentencia No. 001-18-PJO-CC, Caso No. 0421-14-JH de 20 de junio de 2018. Jueza ponente: Wendy Molina.

Corte Constitucional del Ecuador. Sentencia No. 134-13-EP/20, Caso No. 0134-13-EP de 22 de julio de 2020. Juez ponente: Agustín Grijalva.

\section{Jurisprudencia ordinaria}

Corte Nacional de Justicia del Ecuador. Sala de Casación Penal, Penal Militar y Penal Policial. Resolución No. 0145-2015 de 20 de julio de 2015. Juez ponente: Rocío Salgado Carpio. 